\title{
Building communities while building food systems
}

Review by Gregory Zimmerman *

Lake Superior State University

Review of Growing Livelihoods: Local Food Systems and Community Development, by Rhonda Phillips and Christopher Wharton. (2016). Published by Routlege/Taylor \& Francis. Available as hardcover, paperback, and ebook; 270 pages. Publisher's

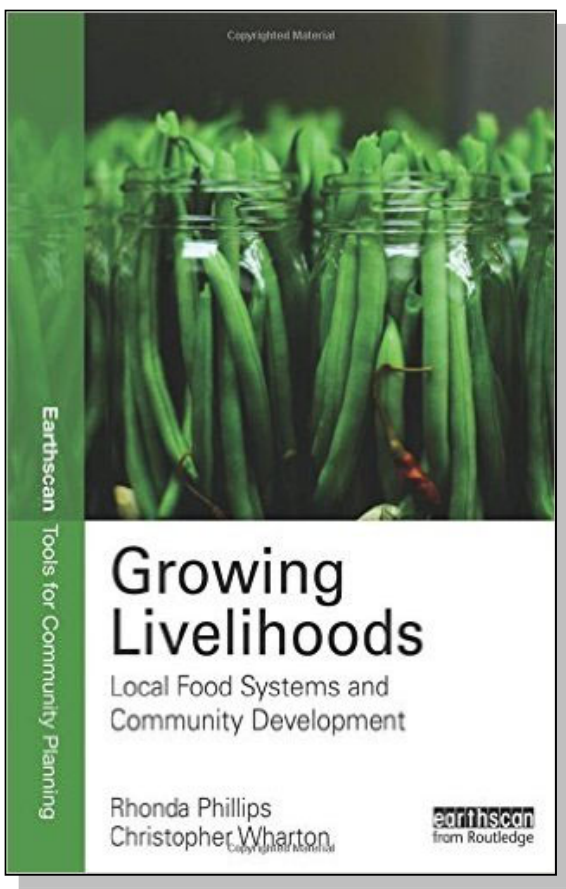
website: https://www.routledge.com/Growing-Livelihoods-Local-Food-Systems-and-CommunityDevelopment/Phillips-Wharton/p/book/9780415727068

Submitted November 28, 2016 / Revised January 24, 2107 / Published online March 3, 2017

Citation: Zimmerman, G. (2017). Building communities while building food systems [Book review]. Journal of Agriculture, Food Systems, and Community Development, 7(2), 149-151. http://dx.doi.org/10.5304/jafscd.2017.072.007

Copyright (C) 2017 by New Leaf Associates, Inc.

$\mathrm{T}$ he title of the journal you are reading is Journal of Agriculture, Food Systems, and Community Development. That title suggests that there is a strong

* Gregory Zimmerman, Professor of Biology, Lake Superior State University; 650 West Easterday; Sault Sainte Marie, Michigan 49783 USA; gzimmerman@LSSU.edu

Gregory Zimmerman is a professor of Biology at Lake Superior State University, where he teaches in the area of ecology, biostats, and epidemiology. His research includes sustainable local communities, food systems, and environmental conservation. He and his family have a small, diverse farm on which they grow produce for the local farmers market, community supported agriculture (CSA) customers, and local restaurants. tie between food systems and community development. In general discussions around food systems and as those of us who work in food systems go about our specialized work, that tie is not always clear, though it should be. Growing Livelihoods: Local Food Systems and Community Development helps make it clearer. With fewer than 250 pages, it is not an encyclopedic treatment of food systems and community development but rather an overview of what can be and is being done in communities around the country.

The authors are Rhonda Phillips, professor in the Department of Agricultural Economics and 
dean of the Honors College at Purdue University, and Christopher Wharton, a nutrition professor at Arizona State University. They bring extensive, practical, first-hand experience in building communities while building food systems. Twelve additional contributors bring even more perspective and experience ranging from research to policy analysis to on-the-ground work.

Phillips and Wharton set the premise for the book in the preface, namely "this book is intended for anyone interested in eating better and fostering better quality of life in their own communities." But an even better description of the book is in Chapter 1: "the model organizations we highlight throughout [this book] represent some of the best ways we have seen to grow local food systems while also improving livelihoods and community well-being."

In setting up the book for later discussion, Chapter 1 is wide-ranging, from the role of food in culture to food security and sovereignty, to sustainability, with a focus on how local food systems can help advance those concerns. The authors also provide sufficient background for readers to appreciate the multiple facets of community development. My work in community development typically centers on the connection between economic development and environmental sustainability. I try to remember that developing a community also means building the capacity for people to participate in decision-making and helping develop new leaders, but again, as we work in our specialized roles, it's easy to lose sight of the larger picture. This chapter helps us all remain focused on that larger picture, and how local food systems can fit into it. A rather long sidebar explains the Sustainable Livelihood Framework, which can bring a broader perspective to economic development that incorporates sustainability and social justice, though the later chapters do not return specifically to this model. The chapter concludes with Wendell Berry's essay "The Pleasures of Eating" to show the connections between food and the general well-being of individuals and communities.

Subsequent chapters address components of food systems and describe leverage points, areas in which initiatives can lead to better communities through a better food system. Topics include direct farm-to-consumer sales, improving access to local foods for people at risk of food insecurity, foodbased businesses across the value chain, the role of farmers markets in building community, food hubs, and cooperatives. Each chapter presents stories about initiatives designed to meet needs in specific communities. And these communities are diverse, including Burlington, Vermont; New Orleans; New York City; rural Indiana; Phoenix; and many more. Many of the stories and some entire chapters are written by the people working directly on the programs described, and are accordingly valuable. I will have the students in my food systems seminar read them.

These examples are intended to be inspirations for other communities to develop community while improving food systems. They are inspirational, but including specifics of how they got started, built their constituencies, and overcame barriers could help communities move from inspiration to implementation. The examples would have been more powerful if presented as case studies with lessons learned. The advantage of the inspirational approach that stays out of the implementation details is that the book is a quick, enjoyable read. The disadvantage of that approach is that upon reading about a great project in region $\mathrm{X}$, someone might dive right into starting a similar project in region $\mathrm{Y}$ without fully understanding the prerequisites for success in their region. Successful projects require a needs assessment, an environmental scan, finding champions, securing local buy-in, and much more beyond just a great idea. Readers should understand that the book highlights projects that are working well in their home communities, and is not a guide for how to do such projects themselves.

The final chapter summarizes major themes about building community through building local food systems and emphasizes the role of policy development. To provide further inspiration, an almanac provides an example of a specific initiative in each of the 50 states and Washington, D.C. These summaries, each about a page long, show that good work is going on all across the country, not just in, for instance, Vermont.

This book can help people working across the food system and those working in community 
development see that our work extends beyond our specializations. The book should inspire others to start programs in their own communities or even inspire others to get into this line of work. Read through the book. If one of the examples strikes a chord, look into it further, contact the people who worked on it, and get more of the details you would need to implement a similar project in your community. Our work requires inspiration, but also preparatory work and follow up. I know of (and have worked on) projects that turned out to be somewhat successful, but short-lived. With a more complete understanding of the community, they could have been so much more. 